\title{
Ethical review committees in Sri Lanka: a national framework is required
}

Jennifer Perera ', D. P. Galaboda ', G. Gunawardena'

The Ceylon Journal of Medical Science 2005; 48: 61-65

\begin{abstract}
A questionnaire based study to review the status of the Ethical Review Committee (ERCs) was conducted in universities and research institutes involved in bio-medical and psycho-social research.

Questionnaires were sent to 37 faculties of 11 universities. Thirty faculties responded. The 6 medical faculties were among the 8 faculties that had ERCs. Questionnaires were sent to 10 research institutes and 3 associations. Among 8 institutes and 2 associations that responded, only the Medical Research Institute and the Sri Lanka Medical Association (SLMA) had ERCs. Fifty percent of the ERCs had a specific application form and there was no uniformity in the information obtained from the researchers. Some application forms lacked essential information relevant to ethical review. Information on availability of consent forms, source of funding, investigations, control selection, review of literature, co-investigators' information, educational qualifications of the investigators are some of them.
\end{abstract}

Sixty percent of ERCs had only academic staff or doctors as committee members. The recruitment of members to the committee did not follow a formal process and no institutional guidelines were available for ERC committee members.

In the current context there is a need to establish a national framework for ethical review in Sri Lanka for educating researchers and to regularize ethical review of research.

\section{Introduction}

At present much bio-medical research involving human and animal subjects is being conducted in Sri Lanka. While many of this research goes through a process of ethical review it is possible that some projects are not screened.

However it is a requirement of many internationally published bio-medical journals that a certificate of ethical clearance be available for the research study to be published. The purpose of an Ethical Review Committee (ERC) in reviewing biomedical research is to contribute to safeguarding the dignity, rights, safety and well-being of all actual or potential research participants (1). In other words, the goals of research should never be permitted to override the health, well being and care of research participants. ERCs should also take into consideration the benefits and burdens of research be distributed fairly among all groups and classes of society (2).

ERCs should provide independent, competent and timely review of ethics of proposed studies before commencement of the research. They also need to ensure that there is regular evaluation of the ethics of ongoing studies that received a positive decision. ERCs should be multidisciplinary 
and multi-sectoral in composition, including relevant scientific expertise, balanced age and gender distribution and lay persons representing the interests of the community. Clear procedures for recruiting potential ERC members should be available as ERCs need to have independence from political, institutional, professional and market influences (3).

\section{Objectives}

The study was done to determine the existance of ERCs in Sri Lanka and to study the composition and mode of operation of the existing committees. The data was compared with those recommended by international guidelines.

\section{Methodology}

Information was requested from all universities and institutes involved in biomedical research in Sri Lanka. All faculties of medicine, arts and humanities, science, agriculture and social science research institutes and main professional associations were included in the study. Data were collected using a self administered questionnaire posted to deans of faculties and heads of research institutions.

A copy of the application form used by the respective ERCs for ethical review was requested from all institutes included in the study. The non responders were contacted by telephone and relevant officials were interviewed. The questionnaires and relevant application forms were analyzed.

\section{Results}

Questionnaires were sent to 37 faculties of 11 universities. Thirty faculties responded. Eight faculties had ERCs and among these
6 were independent committees (Medical Faculties of Universities of Colombo, Sri Jayawardenepura, Ruhuna, Kelaniya, Jaffna and Faculty of Arts, University of Colombo) while 2 were sub-committees of the research committee. (Peradeniya Medical and Dental Faculties) All six medical faculties had ERCs. Four medical faculties had specific application forms designed for the purpose. All eight faculties invited the applicant for interview if further clarifications were required.

Questionnaires were sent to 10 research institutes and 3 associations. Eight institutes and 2 associations responded. Among institutes only the Medical Research Institute had a committee and there was no specific application form. Among associations, the Sri Lanka Medical Association (SLMA) had an ERC and an application form. The applicant was called for an interview if clarifications were required.

Project title, principle investigators' information, objectives of the study, research methods, details about medical procedures / interventions/treatments, data analysis plan, consent procedures, subject selection criteria, potential risks to the participant, benefits, incentives and payments to the subjects were details requested in the application forms and were common to all application forms reviewed. All ERCs requested information on the maintenance of confidentiality of data in their application forms.

One ERC of a Faculty of Medicine also requested information from applicants on specific invasive procedures which was included in the application form as a separate table consisting of a list of invasive and non invasive procedures done on human subjects and the applicant was 
expected to tick the relevant box. They also had separate paragraphs pertaining to use of radioactivity, $x$ rays, medicinal products, medical devices or equipment on study subjects.

Information on the informed consent process, source of funding, investigations, control selection, review of literature, investigators suitability and experience for the proposed study, provisions made for receiving and responding to queries and complaints from research participants were lacking in some application forms. None of the ERCs evaluated the ethics of ongoing studies that received positive decisions.

The majority ( $60 \%)$ of the ERC's did not have a specific time frame for process and review of the applications submitted and this varied from 1-3 months from the date of the receipt of applications.

The composition of the ERCs varied among different committees. Sixty percent $(6 / 10)$ of the ERCs had only academic staff members / doctors of their own institute as committee members, whereas the remaining four committees had members from different nonmedical professions as members.

The recruitment of members to the committee did not follow a formal process of evaluation and no statements on candidacy that includes an outline of duties and responsibilities of members were available to committee members of any of the ERCs. No institutional guidelines were available for ERC committee members.

Three out of the ten ERCs requested a nominal processing fee (range Rs 250 to Rs 1000) for ethical review of research studies.

Five institutes that do not have ERCs requested information and guidelines on setting up of ERCs in their respective institutes although this was not surveyed for in the questionnaire used for the study.

\section{Discussion and Recommendations}

Except for the faculties of medicine majority of the other faculties in universities, research institutes and associations which publicize research do not have a regularized process for ethical review of bio-medical research. Even when an ethical review program was in place, the information requested in the application forms was inadequate and ethically relevant information was lacking in some application forms. The application form for ethical review should address scientific design and conduct of the study, recruitment, care and protection of research participants, issues on confidentiality, informed consent process and relevant community considerations.

The Nuremberg code, 1947 lists the different elements in a study protocol that should be reviewed before providing ethical clearance for the study. However the ERC's in Sri Lanka do not have a uniform protocol where all these elements are addressed in the review process. In all ERC's the process of review was incomplete as one or more of these internationally recommended elements were not addressed during the review of applications. For example a full description of the process of obtaining informed consent has to be reviewed thoroughly as the voluntary consent of the human subject is absolutely essential. The documents of information on the project and informed consent forms should be in a language that could be understood by the potential research participants.

The ERC's in Sri Lanka recruited members to the committees in an ad hoc manner and there was no clear procedure for identifying 
suitable members. Furthermore, once the members are appointed to the committee no clear guidelines are provided that would facilitate their functioning as effective members. With regard to ERC committee membership, clear procedures for identifying or recruiting potential members for ERC should be established (3). Once the committee is selected the conditions of appointment should be made available to the members.

Majority (60\%) of the ERC's did not have a specific time frame for review of applications. It is also important to review the applications sent for review in a timely manner. It is recommended that the decision be communicated to the researcher within two weeks of the meeting. In the case of a conditional decision, any requirements by the ERC including the suggestions for revision should be clearly stated to the researcher. In the case of a negative decision, the reasons should be clearly stated (4).

ERC should establish a follow-up procedure for following the progress of all studies for which a positive decision has been reached, from the time the decision was taken until the termination of the research. This aspect of review was not practiced by any of the ERCs in Sri Lanka. The review intervals are generally determined by the nature and events of research projects. It is recommended that each research project should undergo a follow-up review at least once a year (3).

During the study many faculties and institutes requested information regarding setting up of ERCs in their respective institutes. Many internationally approved guidelines are available for establishing properly functional ERCs in research institutes and universities $(5,6,7,8,9)$. Thus in the current context, establishment of a National framework for providing guidance on setting up ERCs in institutes that conduct biological and psycho-social research would be an important first step in regularizing the process. This would also assist in reforming the existing research committees in the island.

\section{References}

1. International ethical guidelines for biomedical research involving human subjects. Council for International Organizations of Medical Sciences (CIOMS), in collaboration with the World Health Organization (WHO). Geneva (1993).

2. Emanuel E.J., Wendler D., Grady C. What makes clinical research ethical? Journal of the American Medical Association. 2000; 283: 2701-2711.

3. Operational guidelines for ethics committees that review biomedical research (2000) TDR/PRD/Ethics/ 2000.1, World Health Organization, Geneva.

4. Ashcroft R.E., Newson A.J. Reforming research ethics committees. British Medical Journal 2005; 331: 587-588.

5. International Guidelines for Ethical Review of Epidemiological Studies. Council for International Organizations of Medical Sciences (CIOMS), Geneva 1991.

6. Notes for guidance on Good Clinical Practice. International Conference on Harmonization of technical requirements for registration of pharmaceuticals for human use ICH). (CPMP/ ICH/135/ 95) 1 May 1996. 
7. Convention for the protection of human rights and dignity of the human being with regard to application of Biology and Medicine: Convention on Human Rights and Biomedicine. European Treaty Series-No 164. Oviedo, Council of Europe. 4 April 1997.

8. Guidelines for good clinical practice for trials on pharmaceutical products. Annex 3 of The use of essential drugs. Sixth report of the WHO Expert
Committee. Geneva: World Health Organization, 1995: 97-137.

9. Declaration of Helsinki: Recommendations guiding physicians in biomedical research involving human subjects. Adopted by the World Medical Assembly Helsinki, Finland, 1964. Final Amendment at the 48 th General Assembly, Somerset West, Republic of South Africa, World Medical Association, October 1996. 


\section{Instructions to Authors}

The Ceylon Journal of Medical Science 2005; 48: 67-70

Some information to the prospective authors is given below. Detailed instruction on different aspects of publication could be obtained from:

International Committee of Medical Journal Editors, Uniform requirements for manuscripts submitted to biomedical journals: Writing and Editing for Biomedical Publication (Updated October 2005) http://www.icmje.org

\section{Scope}

The Ceylon Journal of Medical Science publishes original research articles from all branches of medicine and allied sciences.

\section{Types of Articles}

Includes original research papers, case reports and leading articles. Any person wishing to write a leading article is requested to consult the editors.

\section{Ethical responsibility}

The authors must ensure that informed consent has been obtained. Authors should state in the methods section, that ethical clearance has been obtained and the experiments were conducted in conformity with guidelines of the Helsinki Declaration. These comments apply to animal research also.

\section{Authorship}

Each author should have participated sufficiently in the work to take public responsibility for the contents of the paper submitted. Participation solely in the collection of data does not justify authorship (see criteria in ICMJE).

\section{Acknowledgements and Other Information}

Acknowledgements will appear as an appendix to the text, and should specify

(a) contributions that need acknowledging but do not justify authorship. The persons concerned should be named and their contribution described - for example, "advice", "critical review of study proposal", and "participation in clinical trial". Such persons must have given their permission to be named.

(b) acknowledgements to technical help, and

(c) acknowledgements of financial and material support

Manuscripts should be accompanied by a covering letter which must include (a) information on prior or duplication or submission elsewhere of any part of the work; (b) that this paper is not under consideration for publication in any other journal concurrently; (c) that the authors agree to transfer the copyright to the Ceylon Journal of Medical Science if the article is selected for publication (d) a statement that the manuscript has been read and approved by all authors, and (e) the name, address, telephone number and e-mail of the corresponding author, who is responsible for communication with the other authors about revisions and final approval of the proofs.

Where appropriate the manuscript must be accompanied by copies of permission to reproduce published material or to use illustrations of identifiable persons. 


\section{Text}

Papers (inclusive of illustrations) should be submitted in triplicate (A4 size) - including the original typewritten copy - typed throughout in double spacing on one side only, with a margin $4 \mathrm{~cm}$ wide at the lefthand side of each page. When submitted they must be in the final form for printing. Additions, amendations and corrections in the proofs add considerably to the editors' duties and to the cost of production. The authors have to submit a computer diskette of the manuscript and illustrations also.

Each page of the manuscript should be numbered and the short title and page number indicated in the upper right-hand corner of each page. Page one should contain the full title, the name(s) of the author(s) followed by initials with full stops, and name and address of the establishment where the work was carried out. In the case of co-authors, respective addresses should be clearly indicated. When a series of related papers is submitted, each individual paper should have the same general heading, followed by a series number and title of the part. Any footnote to the title should be given at the bottom of this page.

The second page should contain an abstract (of not more than 250 words) which should be a summary of the entire paper and intelligible without reference to the paper itself. The text should begin on page three. Each subsequent major section - reference, acknowledgements, should begin on a new sheet. The last page should indicate the number of manuscript pages, figures and tables submitted, the proposed running title and the name and address of the person to whom the proofs should be sent. Paper should be as concise as possible and recognized physical and chemical abbreviation should be used. Abbreviations such as MCHC and MCV may be used as long as, in the first usage, the full term is stated and the abbreviations identified. When mentioning drugs, official and approved names should be always used; trade names may be indicated in addition but these should be in parenthesis. When official or approved names are not available, chemical or trade names may be used. Authors should use SI units. Scientific names of plants, animals and microorganisms will be printed in italics and should be underlined in the manuscript. In the first citation, genus, species and authority must be given:

\section{e.g. Vigna radiate (L), Wilczek}

In later citations, the generic name may be abbreviated to its initial letter:

e.g. V. radiate.

References to other work in the text, tables and legends should be indicated in Arabic numerals in parentheses, referring to the list of references which must be on a separate page at the end of the paper.

\section{Tables}

Tables should be in double-spaces typing on one side only, of A4 sheet with a margin of not less then $4 \mathrm{~cm}$ on the left. Each should be numbered consecutively in Arabic numerals.

Tables should have legends which mak their general meaning clear withou reference to the text and all table column should have explanatory headings. Units $c$ measure should be indicated in the headin of each column. Footnotes to the table shoul be placed directly below the table and shoul be indicated by superscript lower case ital letters $(a, b, c$, etc). The preferred position each table should be indicated in pencil the manuscript. 


\section{Illustrations}

All illustrations are considered as figures. Each figure (graph, drawing, photograph) should be numbered in sequence with Arabic numerals. Each figure should carry a legend so written that the general meaning of each illustration can be understood without reference to the text. The amount of lettering on a drawing should be reduced as far as possible. Legends should be included in their proper place in the typescript and not written in the drawing. Each figure should be identified on the reverse with the running title of the paper and figure number.

Illustrations should be made by line drawings in Indian ink on plain white paper or board and lettered with lettering set. Alternately illustrations and graphs may be prepared by computer - if prepared on a computer it should be sent in a diskette with a print out. The caption of each axis should be lettered parallel to the axis. Photographs should be of good quality, unmounted and prepared on glossy paper, with sharp contrast between black and white areas. Authors may be asked to pay for colour photographs.

\section{References}

Number the references consecutively in the order in which they appear in the text. The reference should include: author's names (in capitals) followed by initials, title of article, title of journal in full, year of publication, volume number in Arabic numerals and the numbers of the first and last pages in Arabic numerals. When reference is made to a book, the author's name should be followed by: title, editor's name and volume number or edition (if appropriate), town of origin and publisher, year of publication and page. The series title of a book should be given in parenthesis after the publisher. List all authors when 5 or fewer; when 6 or more, list only the first 5 and add et al.

The references will then appear in print thus:

1. Wilson W.E. Observations relating to the innervation of sweat glands of the face. Clinical Science 1936; 2: 273-286.

2. Mora J.O. Nutritional assessment by anthropometry. In: Brozek J, Schurch B, eds. Malnutrition and Behaviour: critical assessment of key issues. Lausanne, Nestle Foundation, 1984; 98-106.

3. Zitnack A. In: Chronic cassava toxicity: proceedings of an interdisciplinary workshop, London, England, 24-30 January 1993. Ottawa: International Development Research Centre (IDRCODE) 1973; 84-95.

4. Dews P.B. In Drill V.A., ed Pharmacology in Medicine. 2nd edition New York: Mc Graw Hill, 1958; 309.

5. National Kidney Disease Education Program. Information of health professionals. Bethesda, Md.: National Institute for Diabetes and Digestive and Kidney Diseases, 2004. (Accessed Aug. 31, 2005, at http://www.nkdep.nih.gov/ healthprofessional/index.htm.)

\section{Submitting Manuscripts}

Manuscripts should be mailed under registered cover with adequate protection for figures and the computer diskette to: Professor R.L. Jayakody. Editors, Ceylon Journal of Medical Science, Faculty of Medicine, Kynsey Road, Colombo 8, Sri Lanka. Alternatively the manuscripts could be hand delivered.

\section{Proof}

Corrected proofs must be returned to the Editors without delay. Failure to do so will result in delay in publication. 
Corrections must be restricted to printer's and similar errors, and should be marked in pencil. Any modification of original text should be avoided.

\section{Selection for Publication}

All articles received will be acknowledged to the corresponding author. Each manuscript will be read by one of the editors to decide whether it should be refereed. Those selected for refereeing will be sent anonymously to the referees. Referees are requested to treat papers as confidential material. They are asked to declare any conflict of interest (such as personal ties to authors), and not to copy manuscripts.

The two editors decide on the articles for publication based on the referees comments, of importance of the research problem, scientific strength, clarity of presentation and appropriateness of the article to the readers of the Ceylon Journal of Medical Science. Members of the editorial board are consulted where appropriate. Editors reserve the right to accept or reject articles, modify style, shorten articles, make editorial corrections where necessary, and to determine priority and time of publication. Sometimes editors may accept or reject articles without going through the refereeing process. 